\title{
Psychological impact of the state of emergency over COVID-19 for non- permanent workers: a Nationwide follow- up study in Japan
}

Shota Saito ${ }^{*}$, Huyen Thi Thanh $\operatorname{Tran}^{2}$, Ruan $\mathrm{Qi}^{2}$, Kenji Suzuki ${ }^{2}$, Toru Takiguchi ${ }^{2}$, Kazuo Ishigami ${ }^{2}$, Shinichi Noto ${ }^{3}$, Sachiko Ohde ${ }^{1,4}$ and Osamu Takahashi $i^{1,4,5}$

\begin{abstract}
Background: The outbreak of COVID-19 has caused mental health problems and increased unemployment due to the economic recession. This survey aimed to assess the psychological impact of the state of emergency. We estimated changes in mental health, quality of life, and unemployment experience for general workers during the first COVID-19 outbreak in Japan.

Methods: We conducted a nationwide follow-up study. During the periods of March 26 to April 6, 2020 and June 26 to July 2, 2020, we used the internet to survey general workers aged 15 to 59 years in Japan. The questionnaire items covered employment status and socioeconomic factors, and we used the Center for Epidemiologic Studies Depression Scale (CES-D) and EQ-5D-5L to assess depression and health-related quality of life (HR-QOL), respectively. The differences in outcomes of permanent and non-permanent workers were analyzed using propensity score analysis. A multiple linear regression analysis was performed to examine the relationship between unemployment and CES-D scores.

Results: We included 2351 subjects in the analysis. Changes in both CES-D scores and utility were not significantly different between the two groups. However, a significant difference was found regarding the rate of unemployment, which was associated with higher CES-D scores.

Conclusions: The present study demonstrated that the mental health of non-permanent workers was not negatively affected following the state of emergency due to COVID-19 in Japan. Unemployment is an important factor that influences the mental health of general workers.
\end{abstract}

Keywords: COVID-19, General workers, Mental health, Propensity score analysis, Quality of life, Employment security, Unemployment, Web survey

\footnotetext{
* Correspondence: ssaito@slcn.ac.jp

'Center for Clinical Epidemiology and Health Technology Assessment, St. Luke's International University, OMURA Susumu \& Mieko Memorial St. Luke's Center for Clinical Academia, 5th Floor 3-6-2 Tsukiji Chuo-ku, Tokyo 104-0045, Japan

Full list of author information is available at the end of the article
}

(c) The Author(s). 2021 Open Access This article is licensed under a Creative Commons Attribution 4.0 International License, which permits use, sharing, adaptation, distribution and reproduction in any medium or format, as long as you give appropriate credit to the original author(s) and the source, provide a link to the Creative Commons licence, and indicate if changes were made. The images or other third party material in this article are included in the article's Creative Commons licence, unless indicated otherwise in a credit line to the material. If material is not included in the article's Creative Commons licence and your intended use is not permitted by statutory regulation or exceeds the permitted use, you will need to obtain permission directly from the copyright holder. To view a copy of this licence, visit http://creativecommons.org/licenses/by/4.0/ The Creative Commons Public Domain Dedication waiver (http://creativecommons.org/publicdomain/zero/1.0/) applies to the data made available in this article, unless otherwise stated in a credit line to the data. 


\section{Background}

The coronavirus disease has significantly impacted global public health and has been spreading worldwide. As of August 3, 2020, 17,918,582 COVID-19 cases have been confirmed and 686,703 people have died of the disease worldwide [1]. Many countries have closed their external borders and imposed nationwide lockdowns to successfully-though temporarily-control the spread of COVID-19. However, the countermeasures have led to reduced workforces across all economic sectors, resulting in many job losses [2].

In Japan, the government declared a state of emergency in seven prefectures, including Tokyo and Osaka, on April 7, 2020. Following an upsurge in the "untraceable" new infections, the state of emergency was expanded to the whole of Japan, and 13 prefectures were designated as "special alert areas" on April 16. With the effectuation of the state of emergency, the government urged citizens to refrain from going outside, practice social distancing, stay at home, and follow travel restrictions; non-essential businesses were closed for about a month [3, 4].

The outbreak of COVID-19 has caused mental health problems and increased unemployment due to the economic recession. A large-scale cross-sectional study in China indicated that being at work was associated with lower risks of depression, anxiety, and insomnia [5]. Several studies reported that the rates of depression and anxiety were 18.7 and $21.6 \%$, respectively, among Spanish people during the initial stage of the COVID-19 outbreak; Spanish adults confined due to COVID-19 restrictions of movement showed inverse associations between current physical activity and current perceived anxiety and mood [6, 7].. The Organization for Economic Co-operation and Development (OECD) indicated that the unemployment rate increased $2.9 \%$, reflecting the impact of COVID-19 containment measures [2]. Recently, the Japanese government reported that the mental health conditions of unemployed and non-permanent workers may be particularly vulnerable during the ongoing COVID-19 crisis [8].

The number of non-permanent workers has been increasing in Japan. Precarious employment includes parttime, dispatched, and fixed-term work, and these accounted for 22 and 53\% of all paid employment for males and females, respectively, in 2020 [9]. There was an adverse effect on the mental health of nonpermanent workers due to employment instability, and unemployment status was related to psychological states such as depression, anxiety, and poor health outcomes due to job loss.

A previous study suggested that precarious employment is associated with double the risk of serious psychological distress among middle-aged Japanese men
[10]. Moreover, the transition from full-time permanent employment to another employment status was also associated with the onset of severe depressive symptoms in East Asia [11, 12]. It is well known that poor mental health status, including depression, is an independent risk factor for suicide and is associated with a lower quality of life compared to healthy subjects $[13,14]$.

The current focus on the COVID-19 outbreak is not only the medical outcomes of infected patients but also the mental health of affected individuals and the general population. Therefore, it is meaningful to investigate the changes in mental health and quality of life during the COVID-19 crisis. No study has yet examined the association between employment security and mental health problems after the lifting of the state of emergency in Japan. The aim of this study is to assess the psychological impact of the state of emergency. We estimated changes in mental health, quality of life, and unemployment experience for general workers during the first COVID-19 outbreak in Japan.

\section{Methods}

\section{Study design and data collection}

This nationwide survey was administered online to general workers in Japan aged 15 to 59 years through a platform of more than two million candidates. It was administered by the Cross Marketing Corporation, Tokyo, Japan, which specializes in questionnaire research.

The initial survey was conducted from March 26 to April 6, 2020, before the state of emergency for COVID19 was declared. The follow-up survey was administered to the same cohort of respondants after the state of emergency was lifted, between June 26 and July 2, 2020. The initial survey was administered until data had been collected from 3000 respondents, and the response rate for the follow-up survey targeted $70 \%$ of the initial cohort on the basis of the general response rate for webbased surveys. In the initial survey, we ensured a representative sample of the Japanese population with regards to age, sex, and residential area. The residential area in Japan was divided into 10 regions (Fig. 1). We did not provide any incentives or compensation to the participants for this study.

\section{Questionnaire \\ Working status}

We defined working status as the four types mentioned below; the subjects selected a status during their self-reports.

Permanent employees: Company employees who are guaranteed lifetime employment until retirement, are hired directly by their employers, and have full-time employment. 


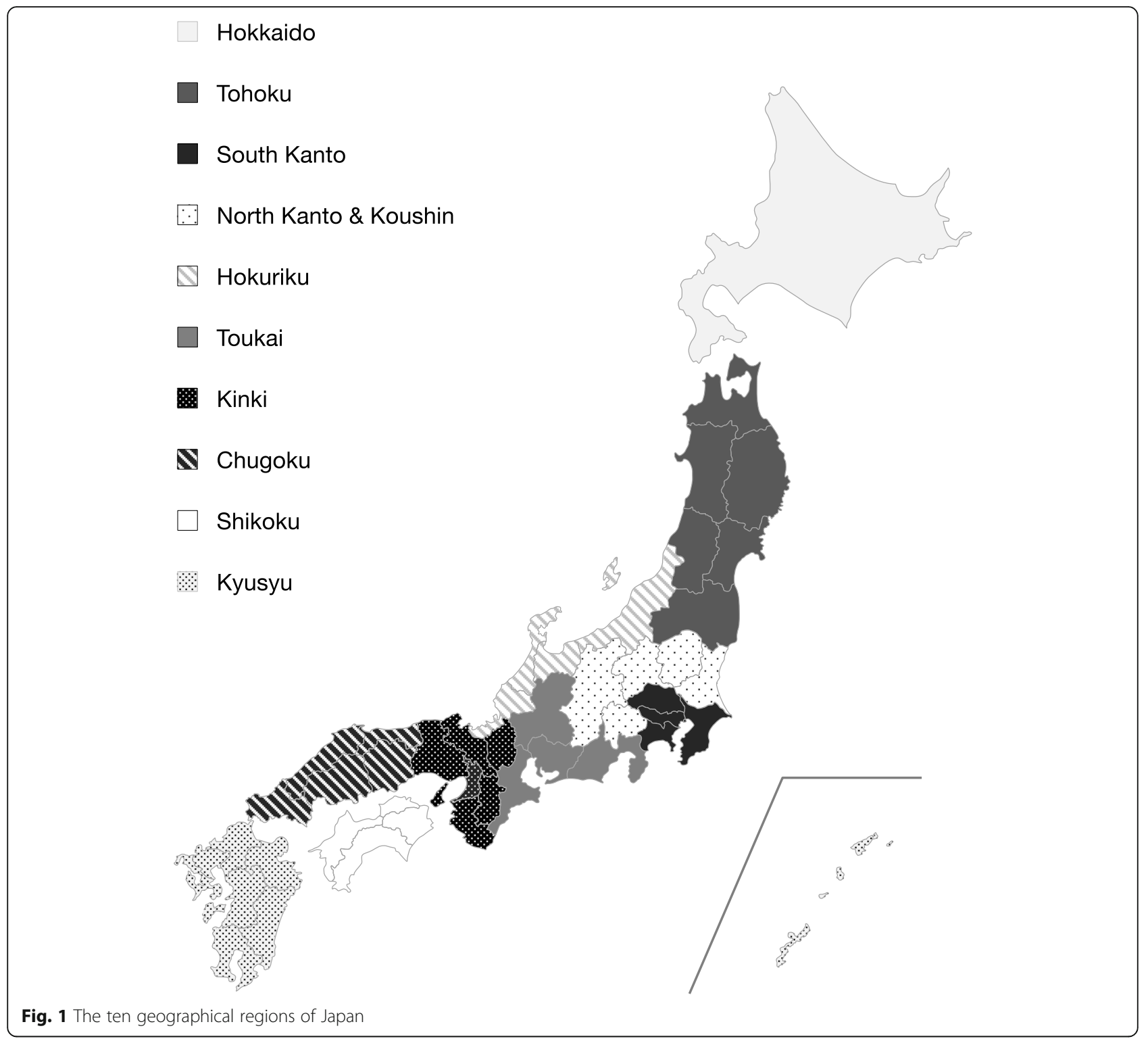

Non-permanent employees: Company employees with fixed-term labor contracts such as part-time employees, dispatched employees from temporary labor agencies, and contract or entrusted employees.

Civil servant: Public service workers in national or local governments who are incorporated into nonprofit organizations.

Self-employed: Self-employed individuals such as sole proprietors and freelancers.

The target population of this study was workers employed by general companies. We excluded civil servants because in Japan, they are guaranteed employment until retirement. We also excluded self-employed individuals because they are not employees.

\section{Socioeconomic status and medical conditions}

The questionnaires covered age, sex, region, marital status, children, family members living together, education, industry, company size, personal income, family income, average overtime per month, labor union membership, householder, exercise, smoking history, drinking history, commute time, and average sleeping time.

We also collected information regarding past medical history such as heart disease, cerebrovascular disease, cancer, Alzheimer's disease, physical disorders with chronic pain, epilepsy, and depression, which are associated with mental conditions, according to the Diagnostic and Statistical Manual of Mental Disorders - Fifth Edition (DSM-5) [15]. The number of diseases was defined 
as a primary factor in this analysis. We used the Japanese version of the sense of coherence (SOC) scale to measure stress-coping ability, with a final score ranging from 13 to 91 . This scale included 13 items, with higher scores indicating better stress-coping ability [16].

\section{Outcomes}

In both the first and second surveys, the degree of depressive symptoms and HR-QOL were assessed. We used the Japanese version of the CES-D to measure depressive symptoms. This scale consisted of 20 items asking participants to rate how often they had experienced symptoms associated with depression over the past week. CES-D scores ranged from 0 to 60 , with scores above 16 usually indicating depressive symptoms. The CES-D has good sensitivity, specificity, and high internal consistency for identifying the risk of depression [17].

We used the five-dimension EQ-5D-5L instrument to assess the respondents' HR-QOL. The EQ-5D-5L consists of five items-namely, mobility, self-care, usual activities, pain/discomfort, and anxiety/depression-rated across five levels. The resulting generic preference-based measure reflects subjective values assigned to specific health-related outcomes ranging from -0.025 to 1 , with 0 indicating death and 1 indicating perfect health in the Japanese value set. We call this score the utility weight [18].

The differences in CES-D scores and utility values between the two timeframes were defined as outcomes in this analysis. We also investigated the unemployment experience during the emergency period in the second survey.

\section{Statistical analysis}

Propensity score matching was performed to adjust for confounding factors between the permanent and nonpermanent groups and to evaluate outcomes [19]. Propensity scores were estimated using a multiple logistic regression model with socioeconomic factors and clinical indicators such as comorbidity and baseline CES-D score and utility. According to their propensity scores, we conducted nearest-neighbor matching with a caliper of 0.2 standard deviations of the propencity score at a 1:1 ratio, without replacement, using the estimated propensity score. In the matched subjects, absolute standardized differences in the means and proportions of those variables were used to confirm the propensity scoring balance between the two groups.

In the matched cohort, we compared the CES-D score changes, utility change, and rate of unemployment experience between permanent and non-permanent employees. Pearson's chi-squared test was used to compare categorical variables, and a Student's $t$-test was used to compare continuous variables. Finally, we assessed the psychological impact of unemployment in terms of changes in CES-D scores. A multiple linear regression analysis was performed to identify the determinants of the changes. Independent variables used in the analysis were working status, unemployment experience, sex, age, number of comorbidities, region, marital status, personal income, family income, average work time per day, labor union membership, householder, exercise, smoking, drinking, average sleeping time, SOC score, and baseline CES-D score. Categorical variables and ordered variables were converted into dummy variables. We considered the interaction of working status and unemployment experience to assess the degree of psychological impact in the two groups.

All statistical tests were two-sided, and $p$-values less than 0.05 were considered significant. All analyses were conducted using STATA 16.1 (College Station, Texas, USA: StataCorp LP).

\section{Results \\ Data collection}

We collected data from 3001 subjects (excluding housewives, students, and unemployed people) in the first survey, and 2351 subjects responded to the follow-up survey. We then excluded 161 self-employed individuals and 132 civil servants from the analysis. Finally, 1373 permanent employees and 685 non-permanent employees were included in the propensity score matching as the permanent and non-permanent groups, respectively (Fig. 2).

\section{Propensity score analysis}

Propensity score matching identified 497 subjects from both the non-permanent and permanent groups. Therefore, we included a total of 994 subjects in the subsequent analyses. Table 1 shows the differences between the baseline characteristics of the non-permanent and permanent groups before and after the matching. All baseline variables included in the model were wellbalanced within the standardized difference or close to 0.1 after matching. The c-statistic of the propensity score was estimated to be 0.862 , ranging from 0.846 to 0.878 , indicating good discrimination between the two groups. We were able to collect the data without any missing values using the web-based survey.

A comparison of changes in the CES-D scores, utility changes, and rates of unemployment between the two groups is shown in Fig. 3. The changes in CES-D scores were estimated to be -0.706 for permanent employees and -0.575 for non-permanent employees $(p=0.807)$. The utility change also did not differ significantly between the two groups (permanent 0.014 vs. nonpermanent $0.009, p=0.533$ ). However, there was a significant difference regarding rate of unemployment, and the data matched (permanent $7.20 \%$ vs. non-permanent 


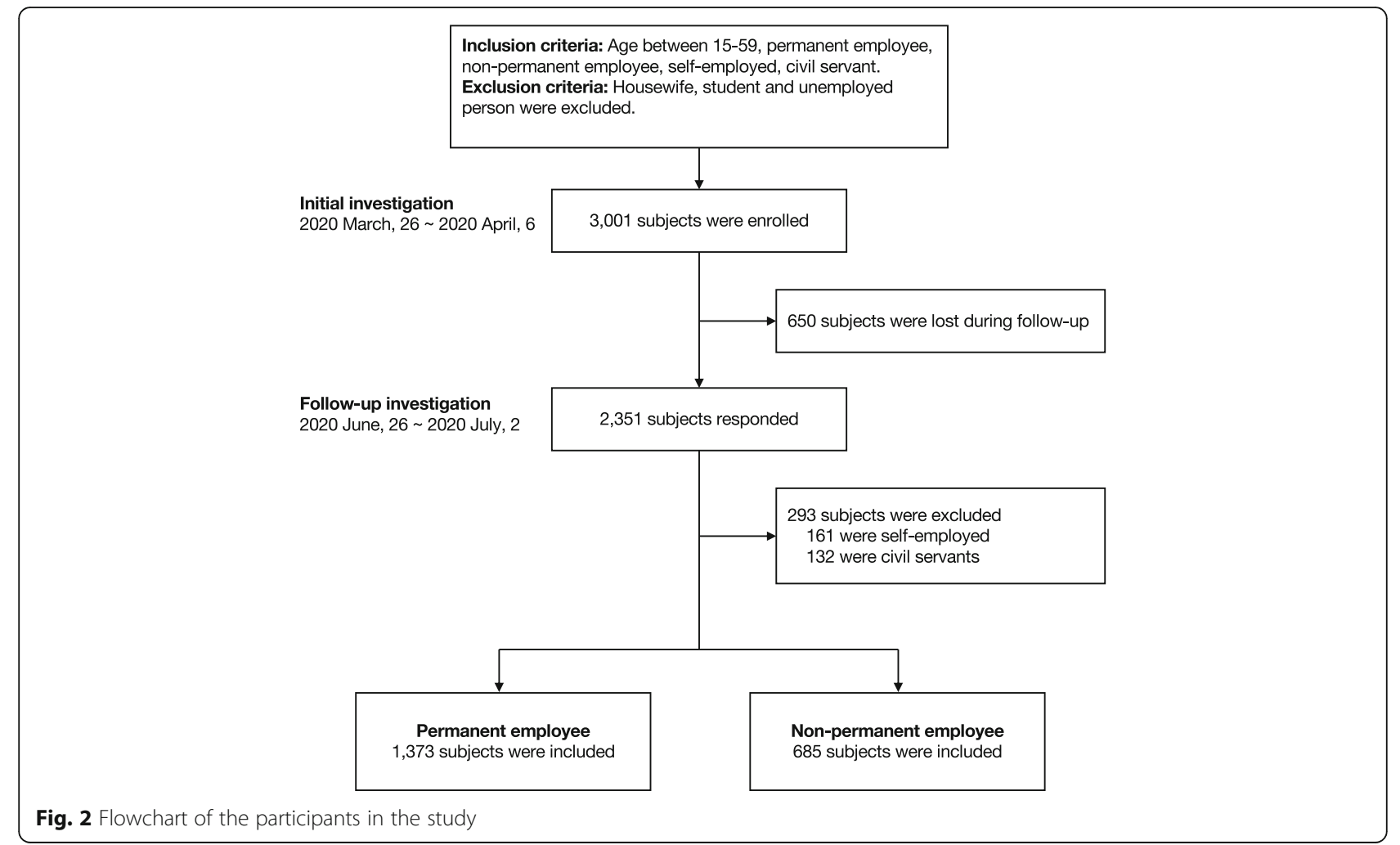

$11.47 \%, p=0.022)$; the risk ratio of unemployment was estimated to be 1.583 (95\% confidence interval $=1.063-$ 2.358).

\section{Multiple linear regression analysis}

The results of the multiple linear regression analysis as presented in Table 2 showed that the unemployment experience was a factor associated with increasing the CES-D score $(p=0.003)$. There were no significant differences in working status and its interaction with unemployment $(p=0.340)$. More than two comorbidities $(p=0.044)$ and average work time per day between 10 to $12 \mathrm{~h}(p=0.027)$ were associated with higher CES-D scores. Specifically, a high SOC score $(p<0.001)$, married status $(p=0.032)$, and a baseline CES-D score $(p<$ $0.001)$ were associated with lower CES-D scores.

\section{Discussion}

The physiological impact of the COVID-19 outbreak is a global concern. In the present study, we examined changes in CES-D scores, health-related utility, and unemployment of general workers during the COVID-19 state of emergency based on data from a Japanese nationwide web-based questionnaire. There were no statistically significant differences in these scores after matching the backgrounds of the subjects. However, unemployment in the non-permanent group was statistically higher than in the permanent group, even after adjusting for baseline factors. Our findings suggest that there was a deterioration of employment conditions, especially for non-permanent workers, after the state of emergency. Unemployment was found to worsen the psychological conditions of general workers in Japan.

Several studies have demonstrated the predictive factors associated with increasing depression and anxiety. In Japan, a cohort study conducted by Sairenchi et al. [20] revealed that SOC may be able to predict the onset of depression in Japanese workers, and Urakawa et al. [21] reported that increasing SOC may reduce negative job stress responses and subjective symptoms for general workers. Recently, a large-scale cross-sectional study conducted by Kikuchi et al. [22] clarified that Japanese workers with longer overtime showed significantly higher anxiety and depression than those with less overtime, among both males and females. Moreover, a Korean study suggested that head of household status, sex, and precarious employment were associated with the onset of severe depressive symptoms [11].

In the propensity score analysis, we adjusted those factors between the permanent and non-permanent groups. There was no statistically significant difference in CES-D scores between the groups; however, there was a slight improvement in the scores of both groups. Although non-permanent workers reported higher rates of unemployment compared to workers with permanent contracts, a significant impact on mental health was not 


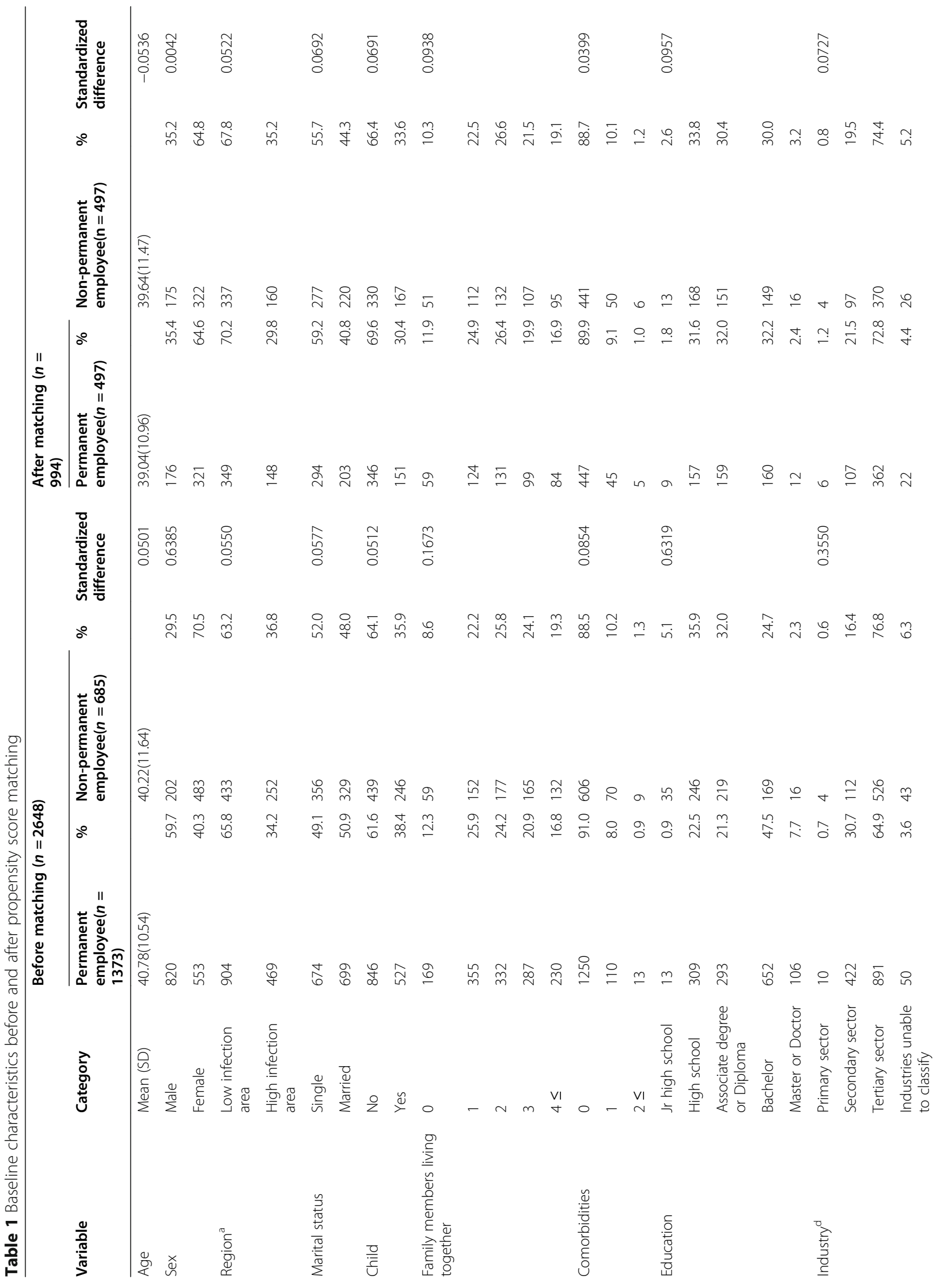


Saito et al. BMC Public Health $\quad$ (2021) 21:334

Page 7 of 12

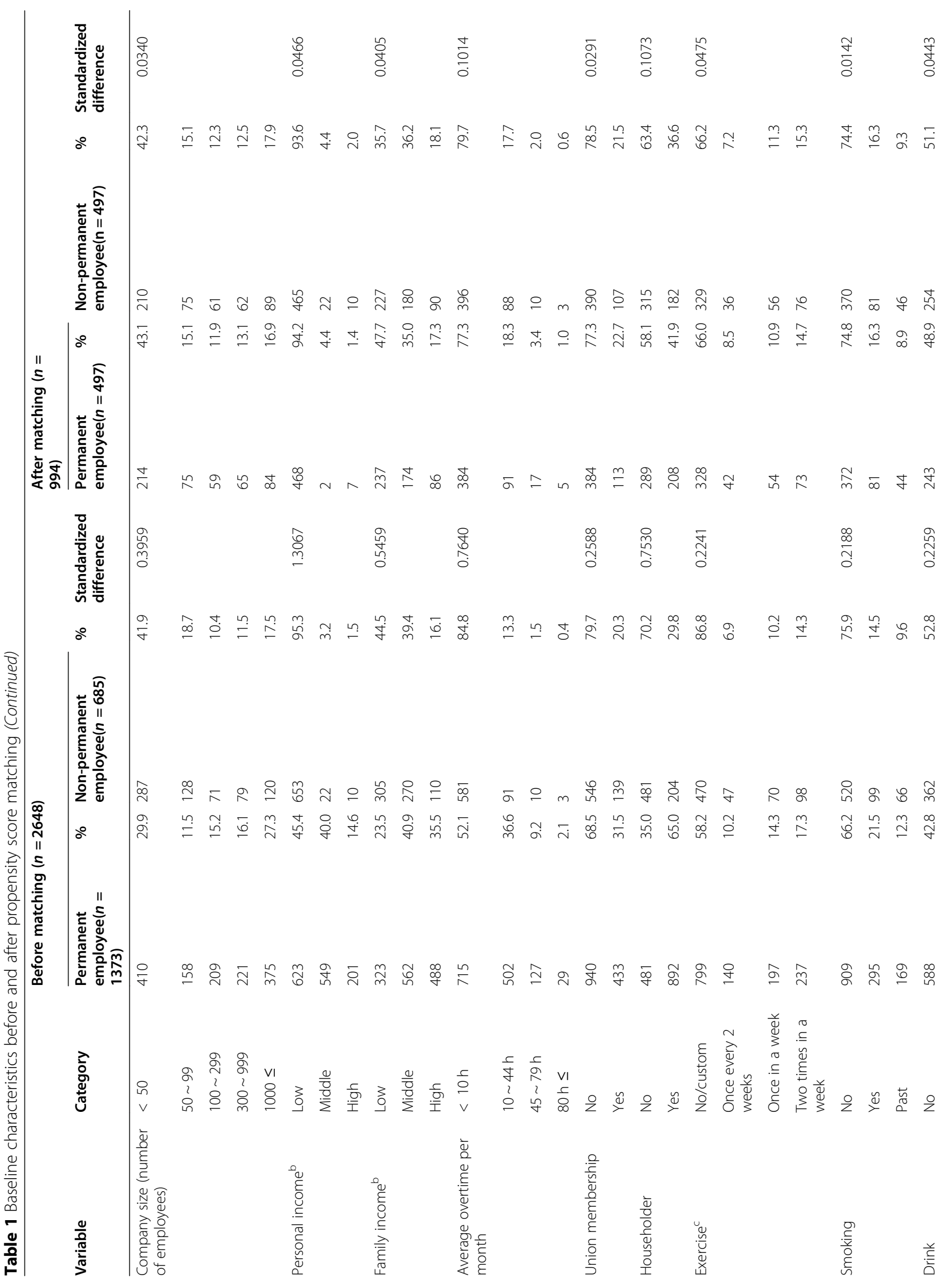




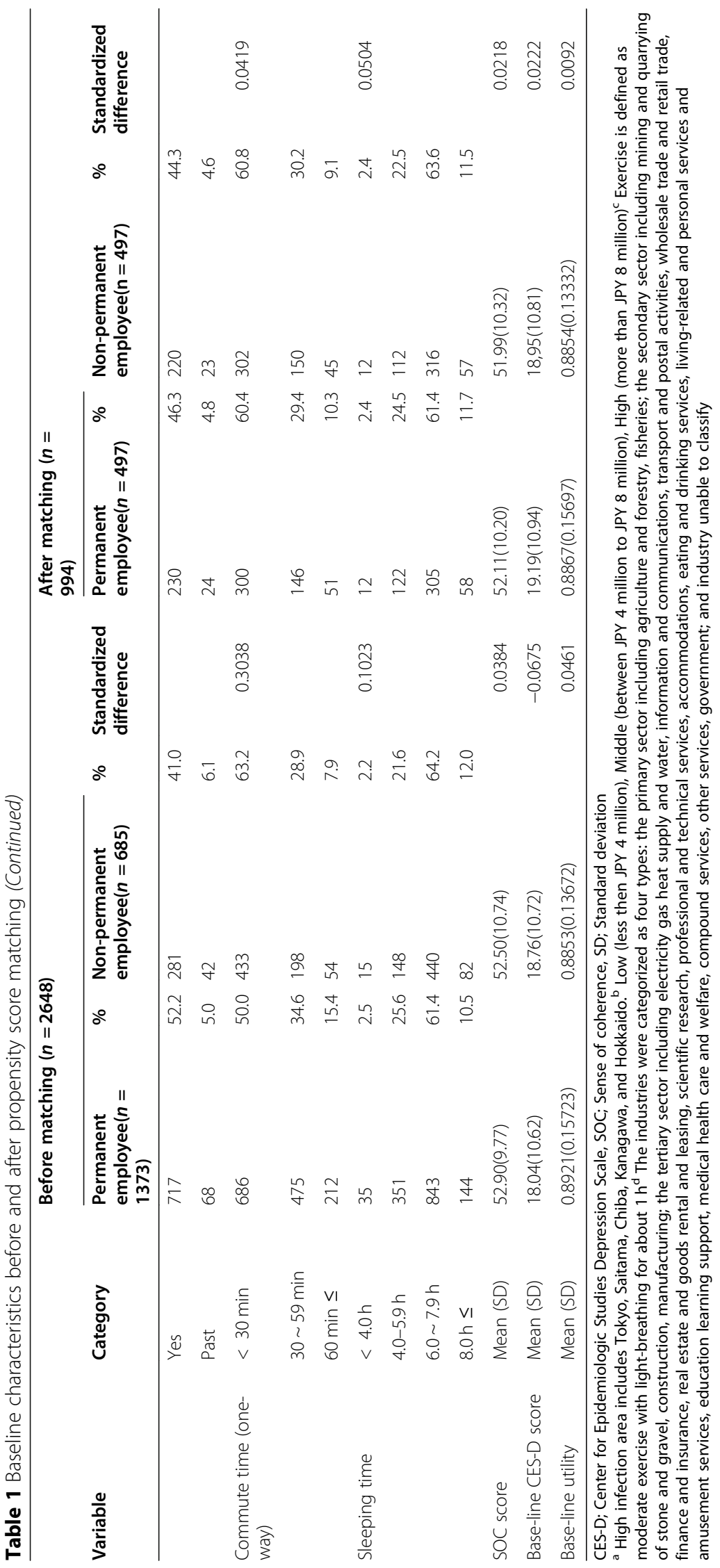




\section{Before matching}
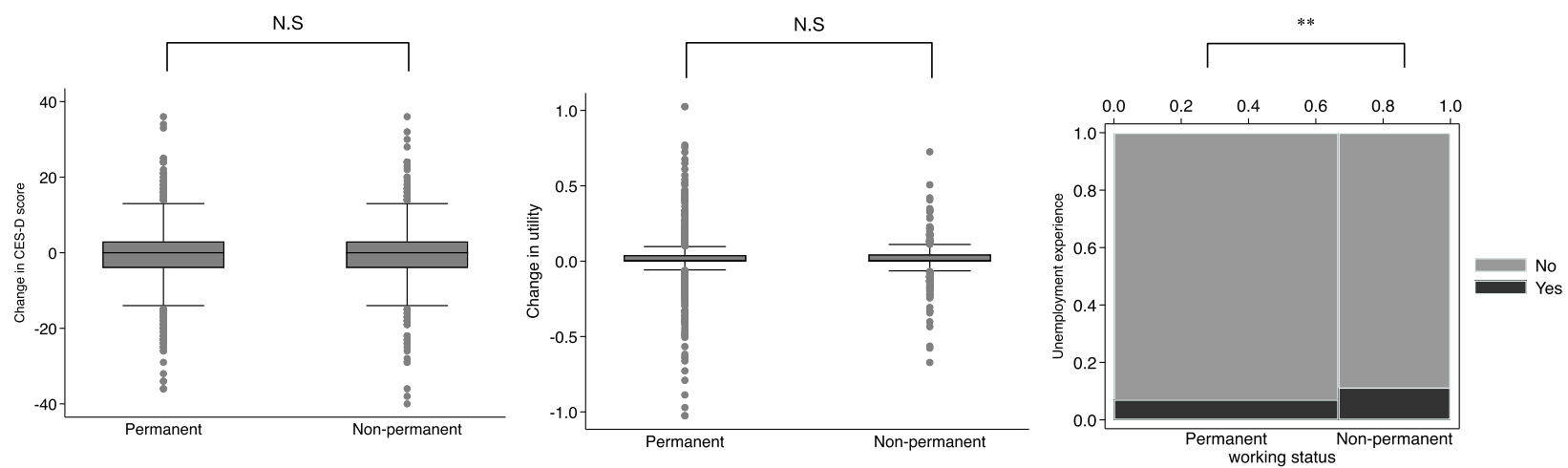

After matching
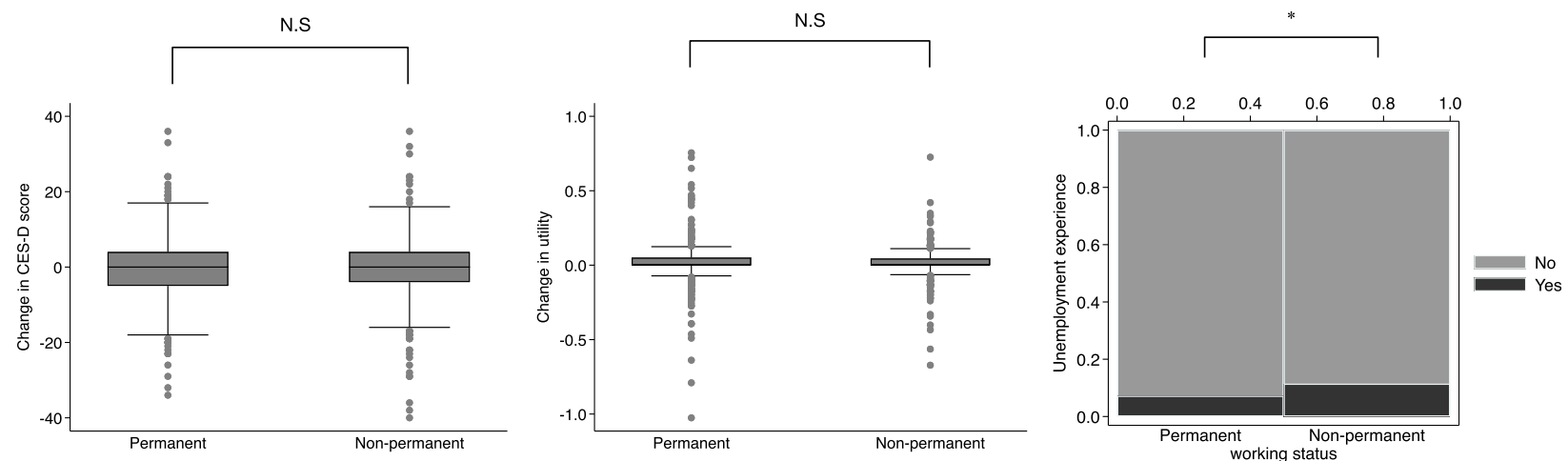

Fig. 3 Box plot of changes in CES-D score and health-related utility, and spine plot of unemployment experience between permanent and nonpermanent groups. (N.S: Not significant, ${ }^{*}: p<0.05,{ }^{* *}: p<0.01,{ }^{* * *}: p<0.001$ )

observed in our data. Our results did not confirm the hypothesis regarding HR-QOL. However, worsening psychological condition affects HR-QOL because the EQ5D-5L includes the dimension of anxiety/depression. We considered that the increasing negative impact on mental health must decrease HR-QOL among nonpermanent workers. Employment security is an important factor in maintaining the mental health of nonpermanent employees. Increasing unemployment could increase suicide rates during and after the COVID-19 outbreak. We suggest that unemployment is a factor that negatively impacts mental health. A previous study indicated that long working hours are associated with an increased risk of depression in Japan. Our multiple linear regression analysis showed similar results [23].

Twenge et al. [24] reported that the prevalence of depression increased slightly in the United States from April 2020 to May 2020. We were unable to estimate the prevalence of diagnosed depression. However, half of the subjects in our data identified depressive symptoms, as indicated by CES-D scores of 16 points or above. Therefore, we considered that this is not an optimistic situation, and an increase in unemployment could lead to an increase in the incidence of depression in Japan in the near future.

Web-based surveys are reliable methods for epidemiological research $[25,26]$. However, this study had several limitations. First, approximately $25 \%$ of subjects were excluded from the follow-up survey because we were unable to obtain a second response through a web survey. Younger participants were not likely to respond to the follow-up survey. Therefore, some selection bias remained in terms of follow-up data compared with initial survey data. However, we believe that such selection bias had minimal impacts on our results because we ensured adequate representation of the Japanese population in the initial survey. Second, we excluded self-employed individuals and civil servants from the analysis as this study targeted workers employed by commercial companies. Civil servants were considered to work in public service, and self-employed individuals typically worked independently. The number of subjects was limited in our follow-up data, so further data collection will be necessary to examine workers' mental health conditions in future research. 
Table 2 Multiple linear regression models of socioeconomic indicators and changes in the CES-D score $(N=2351)$

\begin{tabular}{|c|c|c|c|c|c|}
\hline Variables & Coefficient & Lower $95 \% \mathrm{Cl}$ & Upper $95 \% \mathrm{Cl}$ & $P$ value & \\
\hline Non-permanent & 0.135 & -0.720 & 0.989 & 0.757 & \\
\hline Unemployment experience & 2.358 & 0.793 & 3.923 & 0.003 & ** \\
\hline Non-permanent * Unemployment experience & -1.148 & -3.507 & 1.210 & 0.340 & \\
\hline Sex & -0.301 & -1.055 & 0.452 & 0.433 & \\
\hline Age & -0.015 & -0.050 & 0.020 & 0.397 & \\
\hline \multicolumn{6}{|l|}{ Number of comorbidities } \\
\hline 0 (base) & 1.000 & & & & \\
\hline 1 & 0.939 & -0.238 & 2.116 & 0.118 & \\
\hline More than 2 & 3.284 & 0.092 & 6.476 & 0.044 & * \\
\hline High infection area & 0.566 & -0.125 & 1.256 & 0.108 & \\
\hline Married & -0.821 & -1.570 & -0.072 & 0.032 & * \\
\hline \multicolumn{6}{|l|}{ Personal income } \\
\hline Low (base) & 1.000 & & & & \\
\hline Middle & -0.078 & -1.122 & 0.967 & 0.884 & \\
\hline High & -0.551 & -2.099 & 0.998 & 0.486 & \\
\hline \multicolumn{6}{|l|}{ Family income } \\
\hline Low (base) & 1.000 & & & & \\
\hline Middle & -0.465 & -1.417 & 0.486 & 0.338 & \\
\hline High & -1.003 & -2.189 & 0.184 & 0.098 & \\
\hline \multicolumn{6}{|l|}{ Average work time per day } \\
\hline Less than $8 \mathrm{~h}$ (base) & 1.000 & & & & \\
\hline Between 8 and $10 \mathrm{~h}$ & -0.091 & -0.888 & 0.706 & 0.822 & \\
\hline Between 10 and $12 \mathrm{~h}$ & 1.574 & 0.179 & 2.969 & 0.027 & $*$ \\
\hline Over $12 \mathrm{~h}$ & 0.467 & -2.210 & 3.145 & 0.732 & \\
\hline Union membership & -0.194 & -0.928 & 0.540 & 0.604 & \\
\hline Householder & 0.235 & -0.617 & 1.087 & 0.589 & \\
\hline \multicolumn{6}{|l|}{ Exercise } \\
\hline None (base) & 1.000 & & & & \\
\hline Once every 2 weeks & 0.531 & -0.639 & 1.701 & 0.373 & \\
\hline Once in a week & 0.537 & -0.472 & 1.545 & 0.297 & \\
\hline More than 2 times in a week & -0.203 & -1.126 & 0.719 & 0.665 & \\
\hline \multicolumn{6}{|l|}{ Smoking } \\
\hline No (base) & 1.000 & & & & \\
\hline Yes & -0.270 & -1.151 & 0.611 & 0.548 & \\
\hline Past & -0.338 & -1.441 & 0.766 & 0.548 & \\
\hline \multicolumn{6}{|l|}{ Drink } \\
\hline No (base) & 1.000 & & & & \\
\hline Yes & -0.604 & -1.306 & 0.097 & 0.091 & \\
\hline Past & 0.011 & -1.527 & 1.549 & 0.989 & \\
\hline \multicolumn{6}{|l|}{ Sleeping time } \\
\hline Less than $4 \mathrm{~h}$ & 0.750 & -1.381 & 2.880 & 0.490 & \\
\hline Between 4 and $6 \mathrm{~h}$ & -0.052 & -0.838 & 0.735 & 0.898 & \\
\hline Between 6 and $8 \mathrm{~h}$ (base) & 1.000 & & & & \\
\hline Over $8 \mathrm{~h}$ & 0.999 & -0.074 & 2.073 & 0.068 & \\
\hline
\end{tabular}


Table 2 Multiple linear regression models of socioeconomic indicators and changes in the CES-D score ( $N=2351)$ (Continued)

\begin{tabular}{|c|c|c|c|c|c|}
\hline Variables & Coefficient & Lower $95 \% \mathrm{Cl}$ & Upper $95 \% \mathrm{Cl}$ & $P$ value & \\
\hline SOC score & -0.134 & -0.172 & -0.097 & $<0.001$ & *** \\
\hline Base-line CES-D score & -0.383 & -0.420 & -0.347 & $<0.001$ & $* * *$ \\
\hline Constant & 14.721 & 11.913 & 17.528 & $<0.001$ & $* * *$ \\
\hline
\end{tabular}

CES-D Center for Epidemiologic Studies Depression Scale, SOC Sense of coherence ${ }^{*}: \mathrm{P}<0.05,{ }^{* *}: \mathrm{P}<0.01,{ }^{* * *}: \mathrm{P}<0.001$

Finally, in the follow-up questionnaire, unemployment was defined as loss of a job or discharge during the state of emergency. We were unable to collect more information regarding reasons for unemployment. Moreover, we were unable to use an additional approach to verify the respondents' socioeconomic statuses or clinical histories because of the anonymous self-reported nature of the survey. Despite these limitations and a short-time prospective investigation, the statistical analysis presented in this study can serve as important information for future health and economic policies related to the COVID-19 crisis in Japan.

After the state of emergency was declared, the Japanese government encouraged citizens to refrain from non-essential travel and to avoid going out unless necessary. Many public and commercial facilities, excluding essential businesses, were strongly requested to close. Although the restrictions were not forceful measures like the lockdowns in some foreign countries, most Japanese people exercised self-restraint until the state of emergency was lifted. Japan succeeded in controlling the virus at the end of June. However, the number of unemployed workers due to COVID-19 was estimated to be 48,206 on August 25, according to the Ministry of Health, Labour, and Welfare in Japan $[27,28]$. Japan seems to be facing a second wave of COVID-19; hence, the difficult situation might continue in the medium- to long-term period. Unemployment is expected to increase in specific industries such as manufacturing, food service, and tourism. Thus, we should carefully observe the changes in mental health and suicide rates.

\section{Conclusion}

In conclusion, this study found that mental health of non-permanent workers was not negatively affected by the COVID-19 state of emergency in Japan. We suggest that unemployment history was a factor associated with decreasing mental health, and about $10 \%$ of nonpermanent workers experienced unemployment between the two periods. The COVID-19 crisis is still in its initial phase; systematized policies, including infection control measures and also economic measures, are required to ensure that the mental health of general workers does not worsen. More studies are needed to evaluate the long-term mental health consequences and the incidence of depression during the COVID-19 crisis in Japan.

\section{Abbreviations \\ OECD: Organization for Economic Co-operation and Development; DSM- 5: Diagnostic and Statistical Manual of Mental Disorders - Fifth Edition; HR- QOL: Health-related quality of life; CES-D: Center for Epidemiologic Studies Depression Scale; SOC: Sense of coherence}

\section{Acknowledgements}

We would like to thank Editage (www.editage.com) for English language editing.

\section{Authors' contributions}

Conception and design of the study: $\mathrm{SS}, \mathrm{HH}, \mathrm{RQ}$, and $\mathrm{KS}$; Interpretation of the data: SS and SN; Statistical analysis: SS, SO, and OT; Drafting of the manuscript: SS and SO; Administrative support: OT; Financial support: SS, KS, $\mathrm{T}$, and $\mathrm{Kl}$; Final approval of manuscript: All authors.

\section{Funding}

This study was supported in part by the Japan Society for the Promotion of Science KAKENHI (Grant number 19 K19367).

\section{Availability of data and materials}

The data that support the findings of this study are available from the corresponding author upon reasonable request.

\section{Ethics approval and consent to participate}

The study was approved by the medical ethics committee of Niigata University of Health and Welfare (No. 18385-200318; date April 18, 2020), and it was conducted in accordance with the principles of the 1964 Declaration of Helsinki and its later amendments. Informed consent was obtained from all participants or, if subjects were under 18, from a parent or legal guardian. The data were completely anonymous in the survey.

\section{Consent for publication}

Not applicable.

\section{Competing interests}

The authors declare that they have no competing interests.

\section{Author details}

${ }^{1}$ Center for Clinical Epidemiology and Health Technology Assessment, St. Luke's International University, OMURA Susumu \& Mieko Memorial St. Luke's Center for Clinical Academia, 5th Floor 3-6-2 Tsukiji Chuo-ku, Tokyo 104-0045, Japan. ${ }^{2}$ Field of Health Informatics and Business Administration, Graduate School, Niigata University of Health and Welfare, Niigata, Japan. ${ }^{3}$ Department of Occupational Therapy, Niigata University of Health and Welfare, Niigata, Japan. ${ }^{4}$ Graduate School of Public Health, St. Luke's International University, Tokyo, Japan. ${ }^{5}$ Department of General Internal Medicine, St. Luke's International Hospital, Tokyo, Japan.

Received: 27 November 2020 Accepted: 29 January 2021

Published online: 11 February 2021

\section{References}

1. World Health Organization. Coronavirus disease 2019 (COVID-19) Situation; 2020. p. 196. https://www.who.int/emergencies/diseases/novel-corona virus-2019/situation-reports. Accessed on 7 August, 2020

2. Organization for Economic Co-Operation and Development (OECD). Record rise in OECD unemployment rate in April 2020. (2020) http://www.oecd.org/ sdd/labour-stats/unemployment-rates-oecd-update-june-2020.htm . Accessed on 27 August, 2020. 
3. Looi MK. Covid-19: Japan prepares to extend state of emergency nationwide as "untraceable" cases soar. BMJ. 2020a;369:m1543. https://doi. org/10.1136/bmj.m1543.

4. Looi MK. Covid-19: Japan declares state of emergency as Tokyo cases soar. BMJ. 2020b;369:m1447. https://doi.org/10.1136/bmj.m1447.

5. Shi L, Lu ZA, Que JY, Huang XL, Liu L, Ran MS, et al. Prevalence of and risk factors associated with mental health symptoms among the general population in China during the coronavirus disease 2019 pandemic. JAMA Netw Open. 2020;3(7):e2014053. https://doi.org/10.1001/jamanetworkopen.2 020.14053 .

6. González-Sanguino C, Ausín B, Castellanos MÁ, Saiz J, López-Gómez A Ugidos $C$, et al. Mental health consequences during the initial stage of the 2020 coronavirus pandemic (COVID-19) in Spain. Brain Behav Immun. 2020; 87:172-6. https://doi.org/10.1016/j.bbi.2020.05.040.

7. López-Bueno R, Calatayud J, Ezzatvar Y, Casajús JA, Smith L, Andersen LL, et al. Association between current physical activity and current perceived anxiety and mood in the initial phase of COVID-19 confinement. Front Psychiatry. 2020;11:729. https://doi.org/10.3389/fpsyt.2020.00729.

8. Ueda M, Stickley A, Sueki H, Matsubayashi T. Mental health status of the general population in Japan during the COVID-19 pandemic. Psychiatry Clin Neurosci. 2020. https://doi.org/10.1111/pcn.13105.

9. Statistics Bureau. Ministry of Internal affairs and communications, Labour Force Survey monthly results. (2020) http://www.stat.go.jp/data/roudou/ sokuhou/tsuki/pdf/gaiyou.pdf. Accessed on June 2020 (Japanese).

10. Kachi Y, Otsuka T, Kawada T. Precarious employment and the risk of serious psychological distress: a population- based cohort study in Japan. Scand J Work Environ Health. 2014;40(5):465-72. https://doi.org/10.5271/sjweh.3442.

11. Jang SY, Jang SI, Bae HC, Shin J, Park EC. Precarious employment and newonset severe depressive symptoms: a population-based prospective study in South Korea. Scand J Work Environ Health. 2015;41(4):329-37. https://doi. org/10.5271/sjweh.3498.

12. Yoo KB, Park EC, Jang SY, Kwon JA, Kim SJ, Cho KH, et al. Association between employment status change and depression in Korean adults. BMJ Open. 2016;6(3):e008570. https://doi.org/10.1136/bmjopen-2015008570.

13. Turecki G, Brent DA. Suicide and suicidal behaviour. Lancet. 2016;387(10024): 1227-39. https://doi.org/10.1016/S0140-6736(15)00234-2.

14. Ina $K$, Hayashi $T$, Nomura $H$, Ishitsuka A, Hirai $H$, Iquchi A. Depression, quality of life (QoL) and will to live of community-dwelling postmenopausal women in three Asian countries: Korea, China and Japan. Arch Gerontol Geriat. 2011;53(1):8-12. https://doi.org/10.1016/j.archger.2010.05.010.

15. Kuroki T, Ishitobi M, Kamio Y, Sugihara G, Murai T, Motomura K, et al. Current viewpoints on DSM-5 in Japan. Psychiatry Clin Neurosci. 2016;70(9): 371-93. https://doi.org/10.1111/pen.12421.

16. Ohta $M$, Higuchi $Y$, Yamato $H$, Kumashiro $M$, Sugimura $H$. Sense of coherence modifies the effect of overtime work on mental health. J Occup Health. 2015;57(3):297-301. https://doi.org/10.1539/joh.14-0164-BR.

17. Lewinsohn PM, Seeley JR, Roberts RE, Allen NB. Center for Epidemiologic Studies Depression Scale (CES-D) as a screening instrument for depression among community-dwelling older adults. Psychol Aging. 1997;12(2):277-87. https://doi.org/10.1037/0882-7974.12.2.277.

18. Shiroiwa T, Ikeda S, Noto S, Igarashi A, Fukuda T, Saito S, et al. Comparison of value set based on DCE and/or TTO data: scoring for EQ-5D-5L health states in Japan. Value Health. 2016;19(5):648-54. https://doi.org/10.1016/j.jva 1.2016.03.1834

19. Austin PC. An introduction to propensity score methods for reducing the effects of confounding in observational studies. Multivariate Behav Res. 2011;46(3):399-424. https://doi.org/10.1080/00273171.2011.568786.

20. Sairenchi T, Haruyama Y, Ishikawa Y, Wada K, Kimura K, Muto T. Sense of coherence as a predictor of onset of depression among Japanese workers: a cohort study. BMC Public Health. 2011;11(205):205. https://doi.org/10.11 86/1471-2458-11-205.

21. Urakawa K, Yokoyama K, Itoh H. Sense of coherence is associated with reduced psychological responses to job stressors among Japanese factory workers. BMC Res Notes. 2012;5(247):247. https://doi.org/10.1186/1756-05005-247.

22. Kikuchi $H$, Odagiri $Y$, Ohya $Y$, Nakanishi $Y$, Shimomitsu T, Theorell T, et al. Association of overtime work hours with various stress responses in 59,021 Japanese workers: retrospective cross-sectional study. PLoS One. 2020;15(3): e0229506. https://doi.org/10.1371/journal.pone.0229506.
23. Nakata A. Long working hours, job satisfaction, and depressive symptoms: a community-based cross-sectional study among Japanese employees in small- and medium-scale businesses. Oncotarget. 2017;8(32):53041-52. https://doi.org/10.18632/oncotarget.18084.

24. Twenge JM, Joiner TE. U.S. Census Bureau-assessed prevalence of anxiety and depressive symptoms in 2019 and during the 2020 COVID-19 pandemic. Depress Anxiety. 2020. https://doi.org/10.1002/da.23077.

25. Smith B, Smith TC, Gray GC, Ryan MA. Millennium cohort study team. When epidemiology meets the internet: web-based surveys in the millennium cohort study. Am J Epidemiol. 2007;166(11):1345-54. https://doi.org/10.1 093/aje/kwm212.

26. Ekman A, Dickman PW, Klint A, Weiderpass E, Litton JE. Feasibility of using web-based questionnaires in large population-based epidemiological studies. Eur J Epidemiol. 2006;21(2):103-11. https://doi.org/10.1007/s10654005-6030-4.

27. Ministry of Health, Labour and Welfare. Employment Security. (2020) https:// www.mhlw.go.jp/english/policy/employ-labour/employment-security/index. html. Accessed on 27 August, 2020.

28. Japan Institute for Labour Policy and Training. Results of the "Survey on the Impact that Spreading Novel Coronavirus Infection has on Work and Daily Life." (2020) https://www.jil.go.jp/english/index.html . Accessed on 27 August, 2020.

\section{Publisher's Note}

Springer Nature remains neutral with regard to jurisdictional claims in published maps and institutional affiliations.
Ready to submit your research? Choose BMC and benefit from:

- fast, convenient online submission

- thorough peer review by experienced researchers in your field

- rapid publication on acceptance

- support for research data, including large and complex data types

- gold Open Access which fosters wider collaboration and increased citations

- maximum visibility for your research: over $100 \mathrm{M}$ website views per year

At BMC, research is always in progress.

Learn more biomedcentral.com/submissions 